\title{
AC 2012-4033: EVALUATING THE ACQUISITION OF ENGINEERING CONFIDENCE AND SKILLS THROUGH ROBOTICS
}

\section{Alyssa M. Batula, Drexel University}

Alyssa Batula received her B.S. in electrical and computer engineering from Lafayette College in 2009. She received a M.S. in electrical engineering from Drexel University in 2011 and is currently pursuing her Ph.D. at Drexel in the Music, Entertainment, Technoloy Lab (METlab). She is on her second year of a STEM GK-12 Fellowship and was awarded the NSF Graduate Research Fellowship in 2011. Her interests are signal processing and robotics.

\section{T. William Mather, Drexel University}

Bill Mather is a robotics researcher interested in developing high-level models for multi-robot systems. His research focus has been controlling the higher order statistics of an ensemble of robots in order to maximize the ensemble performance.

\section{Gabe Carryon, Drexel University}

Dr. Stuart Surrey, Philadelphia High School for Girls

Mr. Daniel Edward Ueda, Central High School

Daniel Ueda teaches Physics, AP Physics, and Engineering and Robotics at Central High School in Philadelphia, Penn. He also is the head coach of Central's obotics team, the Robolancers. Ueda has been in teaching for eight years. Prior to teaching, he worked as a Mechanical Engineer for various industrial design firms. He holds a M.S. in teaching from Pace University and a B.S. in mechanical engineering from Rensselaer Polytechnic Institute.

Prof. Youngmoo Kim, Drexel University

Dr. Adam K. Fontecchio, Drexel University 


\section{Evaluating the Acquisition of Engineering Confidence and Skills Through Robotics}

\section{1 - Introduction}

In recent years there have been a number of studies that have cited the declining number of US students graduating from 4-year colleges and universities with degrees in science, technology, engineering, and math (STEM) ${ }^{1}$. Going along with this trend is a declining interest in science amongst US middle and high school students. Many educators are looking at the root causes of these issues and special attention has focused on increasing the number of minority and underrepresented groups in STEM disciplines ${ }^{2}$. According to data from the National Center for Education Statistics, women made up $18 \%$ of all US engineering graduates in the year 2000, in 2009 that number had fallen to $16 \%$. Over the same time period the total number of students entering engineering fields grew by $15 \%$, yet the total number of women in engineering remained unchanged.

Deciding to pursue STEM fields is strongly tied to an individual's sense of self-confidence, and self-efficacy, in STEM disciplines ${ }^{3}$. Research shows that while the gender skills gap has decreased, the number of girls entering engineering fields has not increased at the same rate ${ }^{4}$. Part of the reason may be due to girls' negative self-perception of efficacy in STEM ${ }^{4}$. Robotics has been shown to be effective at increasing students' interest ${ }^{5}$ and increasing self-confidence in STEM. Exposure to STEM topics at the primary and secondary levels is important in combating cultural gender-related biases that can develop over time. The work of Baram-Tsabari ${ }^{6}$ showed that girls' interest in science decreases at a faster rate compared to boys from kindergarten to 12th grade, due to a variety of cultural and psychosocial factors. This highlights the necessity for STEM programs to be undertaken at the pre-college level.

The goal of this work is to determine whether participation in a robotics program, in an all-girls setting, increases girls' interest in STEM and willingness to pursue STEM as a career. A number of studies have highlighted robotic's ability to increase student's interest in science ${ }^{5,7}$. However most of these studies have not looked at implementing robotics programs in all female settings. A secondary goal of this work is to examine new techniques used for survey data collection. Most used paper questionnaires to obtain responses, for this work we used a Nintendo Wii as an additional data collection tool. This allowed data to be collected more easily and accurately compared to paper questionnaires. The robotics program in this study was implemented at an all female high school located in Philadelphia, PA. Previous work performed by Weinberg et al. ${ }^{7}$ showed that robotics was effective at increasing girls' positive attitudes towards STEM careers in all female settings.

In the beginning of the 2011-2012 school year, a group of graduate students and high school teachers started a robotics club at the Philadelphia High School for Girls in Philadelphia, PA. It is a magnet public school, which attracts students who are generally more motivated and interested in college than average high school students. The club meets twice a week and competes in two national robotics competitions: FIRST Tech Challenge (FTC) ${ }^{*}$ and SeaPerch ${ }^{\dagger}$.

\footnotetext{
${ }^{*}$ http://usfirst.org/roboticsprograms/ftc
} 
FTC uses LEGO Mindstorms and Tetrix kits as the base materials for the robots. These kits provide a programmable brain in order to control any motors and sensors built onto the robot. The main materials used in building the robots are pre-cut and drilled metal beams, which can be easily screwed together. To further customize the robot, parts can be cut or otherwise modified to achieve the desired functionality. Teams of about 10 students work together to design, build, and control a robot to score points during the competition. Competitions change from year to year, but always include 30 seconds of autonomous control, where robot follows a set of preprogrammed instructions, followed by 2 minutes of remote control using a joystick.

SeaPerch is an underwater robotics competition. Students design and build a robot that operates underwater in order to complete objectives and score points. SeaPerch also includes a parts kit containing PVC pipes and connectors, wires, and waterproof motors. teams can use additional parts as long as the total value of these parts is less than $\$ 25$. This competition introduces different concepts and constraints such as buoyancy, propulsion, and waterproofing. SeaPerch is supported in part by the Office of Navy Research (ONR).

The goal of this club, an after-school extracurricular activity, is to introduce students to the STEM disciplines through a fun and engaging activity. Additionally, the club aims to teach students engineering skills and critical thinking abilities while increasing their confidence in their engineering skills. Ideally, this experience will encourage students to seriously consider careers as engineers and enroll as engineering majors in college.

In addition to creating a robotics club, we explore methods of assessing the club's effectiveness. Students were given a modified version of the AWE Core Survey for High School Aged Participants ${ }^{\ddagger}$. This written questionnaire assesses student confidence and interest in science and engineering. In order to provide more quantitative data that is not based on student opinion, we used a game for the Nintendo Wii called Big Brain Academy (BBA). BBA tests a player's ability to solve mental challenges and provides a score at the end of each test. We are exploring the use of this provided score to evaluate student skills in logic and spatial reasoning, both of which are important engineering skills. In addition to providing a different type of data, this test is typically more enjoyable to complete than a written survey. The tests used are explained in detail in Section 3.

\section{2 - Background and Motivation}

This initiative is partially the result of a partnership between graduate engineering students and Philadelphia high schools through the NSF GK-12 program ${ }^{\S}$. Ten Drexel University graduate students pursuing a Ph.D. in engineering are paired with ten high school teachers in order to incorporate engineering concepts into the high school curriculum. Within this program there are three graduate students who perform research in robotics and a high school teacher who has

\footnotetext{
${ }^{\dagger} \mathrm{http} / / /$ seaperch.org

${ }^{\ddagger} \mathrm{http}$ ://aweonline.org

${ }^{\S}$ http://gk12.org/
} 
already started a successful robotics club at a neighboring school. This group provides experience and mentorship for the newly founded club.

We chose to use a robotics club as a form of STEM outreach for a variety of reasons. One of the teachers at the Philadelphia High School for Girls has wanted to start a robotics program for the past several years. However, he lacked the background knowledge and experience to start this club on his own. The previously mentioned robotics experience and expertise within the GK-12 program provided the support needed to start the club. Additionally, robotics competitions are already in place which provide pre-existing structures, support systems, materials, and goals for the club. This allows us to maximize our contributions to the club by building on what other people have already accomplished. Outreach activities such as this are run primarily by volunteers: teachers and graduate students who devote their evenings to mentor students. Therefore, it is important to use this time as efficiently as possible by taking advantage of existing resources.

\section{3 - Evaluating Student Opinions and Skills}

At the start of the year, 28 students were evaluated using a written survey by AWE to measure their confidence and interest level in science and engineering. In addition, 24 students were also tested using the game Big Brain Academy to measure their spatial reasoning and logic skills. A follow-up survey was given to 16 students halfway through the year (December 2011) and a final survey will be given at the end of the year, along with another test using BBA. The differences in the number of students tested are the result of the student retention rate. Several students showed up and took the paper survey, but did not return to take the test on the Wii.

The use of BBA to evaluate student skills is intended to compliment the written surveys on students' self-reported confidence and interest in engineering. The goal is to quantify changes in spatial reasoning and logic, important engineering skills, during the course of the year. Using this type of testing was also a convenient method of gathering data. The game was relatively easy to acquire and provides a score, based on speed and accuracy, at the end of each test for use in analysis. Prior studies have indicated a possible correlation between certain games and general intelligence ${ }^{8}$. We chose to explore this as a potential marker of progress in student skills.

In addition to looking for an efficient way to collect data, we also hoped to find a test that was fun for the students to complete. We were concerned that if we gave the students a series of tests at the start of a brand new club they would quickly loose interest and quit. Our concerns were strengthened by student responses to the paper surveys. While most completed them without a problem, several commented that they didn't like having to take the survey or felt that it was too long. It was clear that many of them hurried through the questions in order to return to the club meeting. Presenting the test as a game helped to alleviate boredom and lack of interest. Students were more likely to see it as a fun game rather than a required test.

Using BBA for testing had unintended benefits as well. Several teachers and many students noticed the games set up in the classroom after school and stopped in to see what was going on. This helped create interest in the club and publicize it throughout the school. Many of the students who asked about the game joined the club in order to see what it was like and play the 
game. Membership quickly jumped from approximately 15 to almost 30 students after the game was introduced in the second week. Several of these newly recruited students chose to remain in the club when they otherwise may never have joined at all.

The students were tested on four different games at the start of the club: Train Turn, Match Blast, Block Spot, and Reverse Retention. Screen shots of these games are shown in Figure 1. In Train Turn, the player is presented with a partially completed train track and a goal the train must reach. New pieces of track can be placed to make the train go left, right, or forward from the perspective of the train. Match Blast also requires spatial reasoning. It displays a twodimensional shape and a stacked set of blocks to the player. The objective is to match the shape by removing the correct blocks. Block Spot requires the player match rotating 3-D shapes. Each shape is made from a $3 \times 3 \times 3$ cube of blocks. Finally, Reverse Retention tests memory and reasoning by asking the player to repeat a shown sequence in reverse from memory.
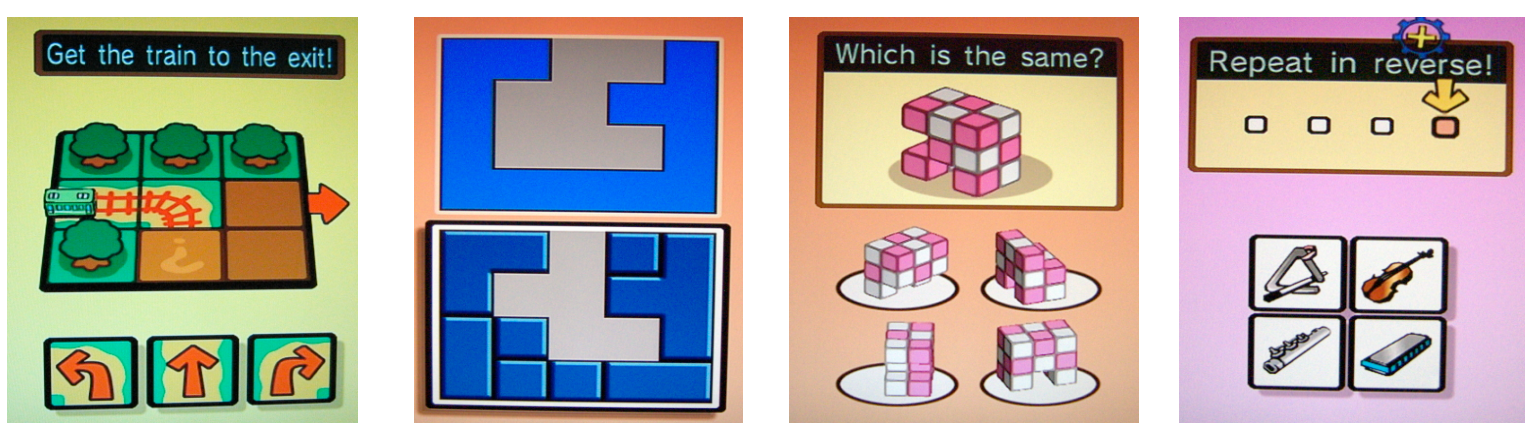

Figure 1: Screen shots of the games, left to right, Train Turn, Match Blast, Block Spot, and Reverse Retention.

\section{4 - Skill Evaluation}

The scores received from games of BBA range from 0 (completely incorrect) to over 2000. Most students had never played the game before, but many were familiar with the Wii console itself. The highest score recorded during the initial test was 322 in the game Block Spot, and there were many instances where students scored 0 points for a round. Students performed the best with Reverse Retention and Block Spot, with average scores of 146.7 and 142.2, respectively. Match Blast and Train Turn were more difficult, scoring 105.2 and 101.5 , respectively.

The low score for Train Turn was particularly interesting, since it correlated with the students' difficulty driving the robot. The Train Turn game requires the player to be able to give directions from the perspective of the train. This is similar to driving the robot, where commands must be given with respect to the direction the robot is facing. During preparation for the FTC competition, one of the major difficulties was that the students could not navigate the robot through the field. 


\section{5 - Retention Results}

As part of this intermediate report of the robotics club progress, we wanted to analyze why the students in the robotics club remained in the club. The students who took the second survey were considered to be in the club, and any students who came infrequently enough to miss the second round of surveys were considered to have left the group. Using an AWE pre-survey, we hypothesized four possible effects that led to retaining the students.

Hypothesis \#1 - The retained students had listed more reasons for joining the group. Using the pre-survey question shown below, the students entered their reasons for joining the club. We then scored each student by the number of reasons they checked off. We hypothesized that the students who initially entered more reasons to join the group would be more likely to remain with the group.

18. Why did you choose to attend this activity? Check all that apply.

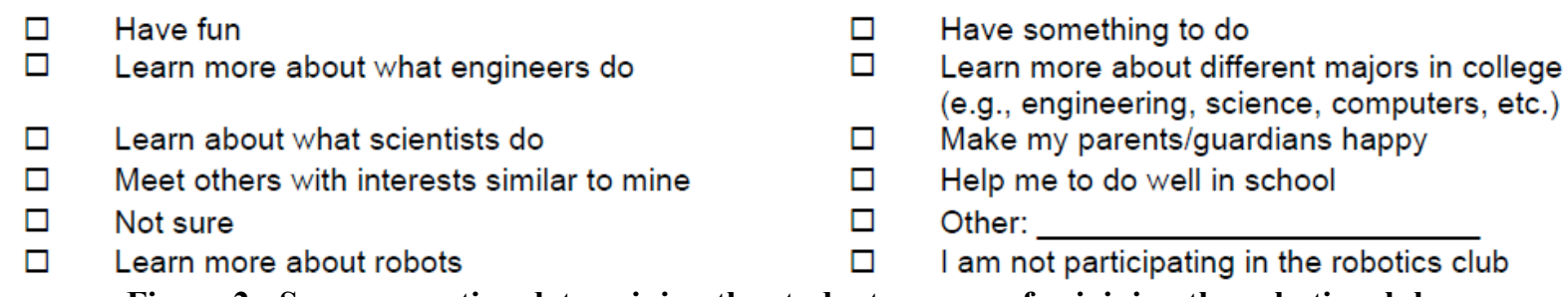

Figure 2 - Survey question determining the students reasons for joining the robotics club.

Hypothesis \#2 - The retained students expressed a higher level of self confidence.

Using a series of Likert questions from the pre-survey that measured self-confidence in the students, we hypothesized that the students in the retained group would score higher. The higher self-confidence levels would help the students be more prepared to handle the incomplete nature of design problems encountered within the activities of the robotics club. The self-confidence score was compiled by assigning a numerical score to each Likert response (never $=1$, always $=$ 4) and then summing the nine responses together. 
16. The table lists things you can do when you are working on school activities or assignments. Check the appropriate box to tell us how often you do each of these things.

\begin{tabular}{|c|c|c|c|c|c|}
\hline & & Never & Sometimes & Very Often & Always \\
\hline & $\begin{array}{l}\text { When I see a new math problem, I can use what } \\
\text { I have learned to solve the problem. }\end{array}$ & ( & ( & ( & ( \\
\hline b) & $\begin{array}{l}\text { I can use what I know to design and build } \\
\text { something mechanical that works. }\end{array}$ & ( & ( & ( & ( \\
\hline c) & $\begin{array}{l}\text { In lab activities, I can use what I have learned to } \\
\text { design a solution. }\end{array}$ & ( & ( & ( & ( \\
\hline d) & $\begin{array}{l}\text { I can effectively lead a team to design and build } \\
\text { a hands-on project. }\end{array}$ & 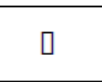 & ( & ( & ( \\
\hline e) & $\begin{array}{l}\text { I know where I can find the information that I } \\
\text { need to solve difficult problems. }\end{array}$ & ( & ( & ( & ( \\
\hline f) & $\begin{array}{l}\text { I can use what I have learned to teach myself } \\
\text { how to program a computer game. }\end{array}$ & ( & ( & ( & ( \\
\hline g) & $\begin{array}{l}\text { I can explain math or science to my friends to } \\
\text { help them understand. }\end{array}$ & ( & ( & ( & ( \\
\hline h) & I can get good grades in math. & ( & प & प & प \\
\hline & I can get good grades in science. & ? & [ & Q & प \\
\hline
\end{tabular}

Figure 3 - Survey questions about the self confidence of the students.

Hypothesis \#3 - The retained students had a higher level of family education at home.

7. What is the highest level of formal education completed by your parents?

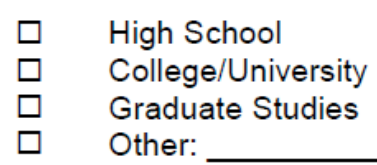

Figure 4 - Survey question about the parent's level of education.

Using the pre-surveys question on the parents level of education. The survey was then scored from zero to three with zero given to students whose parents had not attended/finished high school. Given the example of academic achievement at home we guessed that the students of more educated parents would be more interested in remaining with the club.

Hypothesis \#4 - The retained students had a more agreeable relationship to Math and Science. Using a series of Likert questions gauging a students interest in math and the sciences, shown in Figure 4, a metric on agreeability was formulated by assigning a numerical score to each Likert answer and the summing all of the results together.Strongly Disagree was weighted 1 while Strongly Agree was weighted with a 4 . The students who began the club with a better overall 
attitude towards math and science would be better prepared from the problems encountered in robotics club.

17. Here is a list of statements. Tell us what you think about them. Select a response that indicates your level of agreement.

\begin{tabular}{|c|c|c|c|c|}
\hline & \multicolumn{4}{|c|}{ How much do you agree or disagree with this sentence? } \\
\hline & $\begin{array}{l}\text { Strongly } \\
\text { Disagree }\end{array}$ & $\begin{array}{l}\text { Somewhat } \\
\text { Disagree }\end{array}$ & $\begin{array}{l}\text { Somewhat } \\
\text { Agree }\end{array}$ & $\begin{array}{l}\text { Strongly } \\
\text { Agree }\end{array}$ \\
\hline a) I look forward to science class in school. & ( & Q & 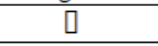 & ( \\
\hline b) I look forward to math class in school. & प & ? & ? & ? \\
\hline $\begin{array}{l}\text { c) I would rather solve a problem by doing an } \\
\text { experiment than be told the answer. }\end{array}$ & ( & ( & ( & ( \\
\hline $\begin{array}{l}\text { d) More time should be spent on hands-on } \\
\text { projects in science or technology activities at } \\
\text { school. }\end{array}$ & ( & ( & ( & ( \\
\hline $\begin{array}{l}\text { e) I would like to (or already do) belong to a } \\
\text { science or technology activities club. }\end{array}$ & ( & ( & ( & ( \\
\hline $\begin{array}{l}\text { f) I get bored when I watch programs on } \\
\text { channels like Discovery Channel, Animal } \\
\text { Planet, Nova, Mythbusters, etc. }\end{array}$ & ( & ( & ( & ( \\
\hline $\begin{array}{l}\text { g) I like to get science books or science } \\
\text { experiments kits as presents. }\end{array}$ & ( & ( & ( & ( \\
\hline h) I like learning how things work. & ( & ( & ( & ( \\
\hline i) Science is too hard when it involves math. & Q & प & Q & Q \\
\hline j) Science is a difficult subject. & प & प & प & प \\
\hline $\begin{array}{l}\text { k) Doing experiments in science class is } \\
\text { frustrating. }\end{array}$ & ( & ( & ( & ( \\
\hline $\begin{array}{l}\text { I) I feel comfortable with using a computer to } \\
\text { make graphs and tables. }\end{array}$ & ( & ( & ( & ( \\
\hline $\begin{array}{l}\text { m) I am interested in learning more about how } \\
\text { computers work. }\end{array}$ & ( & ( & ( & ( \\
\hline n) I like to learn to use new computer software. & Q & [ & Q & [ \\
\hline
\end{tabular}

Figure 5 - Survey questions gauging the attitudes on math and science. 
a) Hypothesis \# 1 Results

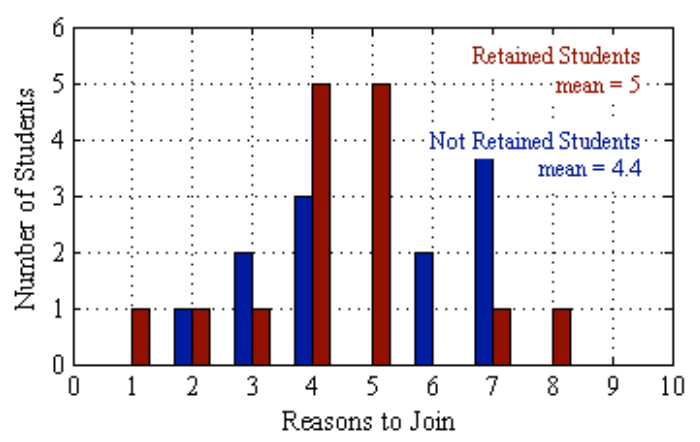

c) Hypothesis \# 3 Results

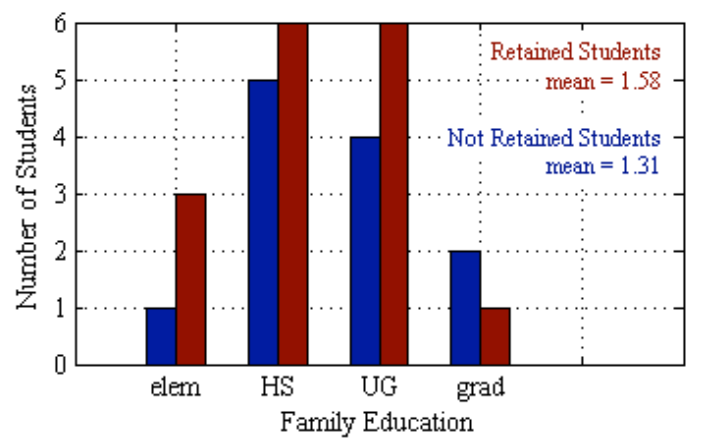

b) Hypothesis \# 2 Results

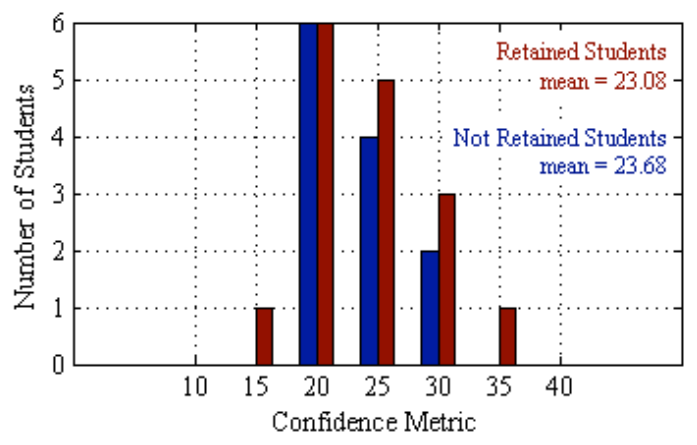

d) Hypothesis \# 4 Results

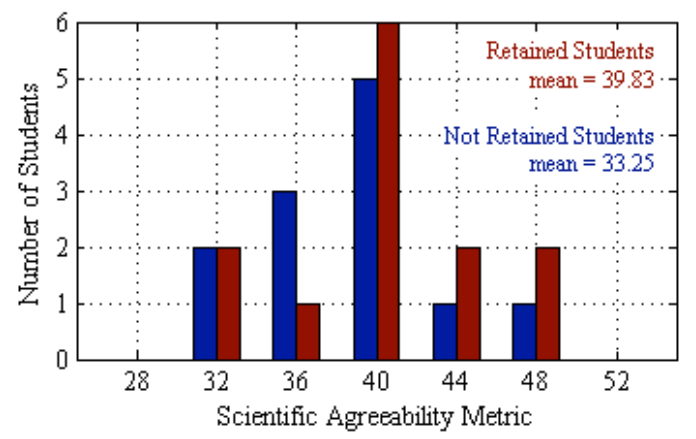

Figure 6(a-d) - Results from the testing the Hypotheses described in section Retention Results. The two sets of students, retained and not retained, were found to be similar given the metrics for a)reasons to join, b)self confidence in the sciences, c)Family Education, and d) Attitude towards science, or agreeability.

The results from analyzing the pre-surveys and comparing it to student retention are shown in Figure 5 (a-d). Each hypothesis was nullified. There was no statistical significance between the our suggested factors and retention in the robotics club. The group of retained students is statistically similar to the students who left the group. Though the mean values for hypotheses 1,3 , and 4 were higher, the data sets were very similar, especially given the very low number of student in the group (28 total).

The Survey results were also analyzed to extract what were the largest contributors towards retention. The covariance between remaining in the club (staying assigned a value of 1, leaving the club, 0) and the other survey questions were analyzed. The three highest positive and negative contributors by correlation are shown in the table below. 


\author{
Positively Correlated \\ I joined robotics club to have something to do. \\ $(+0.14)$ \\ I can effectively lead a team. \\ $(+0.13)$ \\ In lab activities, I can use what I \\ have learned to build a solution.
}

$(+0.11)$

\section{Negatively Correlated}

Work that allows me to help

my community and/or society

$(-0.16)$

More time should be spent on hands on projects in Science and Technology projects at school.

$(-0.14)$

I'm interested in learning more about how computers work.

$(-0.11)$

Table 1 - The most positively and negatively correlated variables related to student retention.

Two of the factors correlated with leaving the club are an interest in hands-on projects and working with computers. Unfortunately, it took several weeks to obtain supplies so that students could start physically building the robot or working with a computer. Many of the students left during this initial period, some of whom probably left due to this lack of supplies. Students who felt confident in their leadership skills, however, tended to stick through this period. They may have felt their managing and organizing skills were still useful as we made plans for the team, even though we did not have the parts yet.

Students who have a strong desire to help their community also tended to leave the club. At this particular school, almost all after-school clubs meet on Tuesday and Thursday, conflicting with the robotics club. A few students in particular told me that they would like to join the club, but it overlaps with other groups such as the Red Cross Club. The students who simply wanted something to do, however, stayed. They may have had less competition for their time if they were still looking for an activity to join. As long as the club was enjoyable enough they were likely to stay.

\section{6 - Conclusions and Current Progress}

The club currently has between 10 and 15 regularly attending students. Mentors include three high school teachers, three graduate students, two undergraduate students, a representative from the Navy, and an associate professor. The time commitment for each mentor varies between 1 and 6 hours per week.

The club is loosely divided into two groups, one for each competition. The team working on FTC entered the regional competition on February $4^{\text {th }}, 2012$ with a fully-functioning robot. Since we are a new club, we kept the design simple. Our goal was to have a controllable robot with one extra component: a door that opens and closes to gather racquetballs in order to score points. This basic design can serve as a starting point for designing a robot in future years. Our team won the Motivate Award for their team spirit and enthusiasm during the competition. 
SeaPerch, which started later, is finalizing their strategy and design for their robot. The underwater robot has been tested in a neighboring school's swimming pool to ensure that is functions properly. Additionally, it allowed the students to practice driving and maneuvering the robot. The competition will take place on March 24, 2012.

There do not seem to be any strong indicators about which students will leave and which will stay with the club. Both the groups that stayed and left the club were statistically similar in their answers to the provided survey questions. This seems to imply that as long as a robotics club is engaging and fun a percentage of students will stay regardless of factors such as self-confidence, family education, agree-ability with math and science, or their motivation for joining the group. A final survey, taken at the end of the year, will hopefully confirm these findings. Additionally, another test using the Wii and Big Brain Academy will hopefully correlate with increased engineering skills.

\section{Acknowledgments}

This work is supported by NSF Award DGE-0947936 and the Graduate Research Fellowship.

[1] R. Atkinson. "Supply and Demand for Scientists and Engineers: A National Crisis in the Making," Science, pp. 12-23, 1990.

[2] M. Laeser, et al. "Engineering Design: Examining the Impact of Gender and the Team's Gender Composition," Journal of Engineering Education, pp. 49-56, 2003.

[3] J.E. Jacobs. 2005. "Twenty-five years of research on gender and ethnic

differences in math and science career choices: What have we learned?" New Directions for Child and Adolescent Development, pp. 85-94, 2005.

[4] R.M. Marra, et al. "Women Engineering Students and Self-Efficacy: A Multi-Year, Multi-Institution Study of Women Engineering Student Self-Efficacy," Journal of Engineering Education, pp. 27-38, 2009.

[5] M. Robinson. "Robotics-driven Activities: Can They Improve Middle School Science Learning?" Bulletin of Science, Technology \& Society, 2005.

[6] A. Baram-Tsabari \& A. Yarden. "Quantifying the Gender Gap in Science Interests," International Journal of Science and Mathematics Education, 2011.

[7] Weinberg et al. "The Impact of Robot Projects on Girls' Attitudes Toward Science and Engineering," in RSS Robotics in Education Conference, 2007.

[8] M.A. Quiroga, M. Herranz, M. Gómez-Abad, M. Kebir, J. Ruiz, Roberto Colom, "Video-games: Do they require general intelligence?," Computers \& Education, Volume 53, Issue 2, September 2009, Pages 414-418, ISSN 0360-1315, 10.1016/j.compedu.2009.02.017. 